\title{
Supraglottic Cancer pT4b TNM Finding v8
}

National Cancer Institute

\section{Source}

National Cancer Institute. Supraglottic Cancer pT 4b TNM Finding v8. NCI Thesaurus.

Code C133107.

Suprag lottic cancer with very advanced local disease. Tumor invades prevertebral space, encases carotid artery, or invades mediastinal structures. (from AJCC 8th Ed.) 